\title{
Colonisation of newly-opened habitat by a pioneer species, Alvinella pompejana (Polychaeta: Alvinellidae), at East Pacific Rise vent sites
}

\author{
Florence Pradillon ${ }^{1,3, *}$, Magali Zbinden ${ }^{1}$, Lauren S. Mullineaux ${ }^{2}$, Françoise Gaill ${ }^{1}$ \\ ${ }^{1}$ UMR 7138 Systématique, Adaptation et Evolution, CNRS, Université Pierre et Marie Curie, 7 quai Saint-Bernard, \\ 75252 Paris Cedex 05, France \\ ${ }^{2}$ Biology Department, Woods Hole Oceanographic Institution, Woods Hole, Massachusetts 02543, USA \\ ${ }^{3}$ Present address: Max Planck Institute for Marine Microbiology, Molecular Ecology Department, Celsiusstraße 1, \\ 28359 Bremen, Germany
}

\begin{abstract}
Animal communities on the walls of deep-sea hydrothermal chimneys are distributed in mosaics of patches that may evolve as local environmental conditions change and biological interactions develop. Alvinella pompejana Desbruyères et Laubier, 1980 is one of the first metazoan colonisers of new surfaces created by mineral precipitation, and therefore may be particularly important in community establishment in active parts of smokers. Here our goal was to investigate the colonisation mechanisms of A. pompejana in new patches and determine whether these mechanisms may influence population structure and reproductive patterns in this species. We deployed a series of TRAC (Titanium Ring for Alvinellid Colonisation) devices at East Pacific Rise (EPR) vent sites to compare the size and stage (i.e. reproductive maturity) distribution of A. pompejana individuals between recently colonised patches (TRACs) and established patches (grabbed by submersible). TRACs deployed for short time periods (11 d to $1 \mathrm{mo}$ ) were generally colonised by smaller individuals than those found in background populations or in TRACs deployed for longer time periods ( $>1 \mathrm{mo})$. Colonists into new patches were a mix of juveniles and individuals that were sexually mature but non-reproductive (i.e. not producing gametes), whereas background population and older patches harboured a mixture of individuals at different stages including reproductive females. Although some individuals may have recruited on TRACs as larvae, the major colonisation process involved was probably immigration of post-larval stages. In long-term TRAC, reproductive females were not reproductively synchronised. In this dynamic environment, reproduction would be triggered by the disturbance/migration processes, explaining the heterogeneity observed in reproductive patterns.
\end{abstract}

KEY WORDS: Polychaete $\cdot$ Hydrothermal vent $\cdot$ Deep-sea $\cdot$ Reproduction $\cdot$ Experimental colonisation Patch distribution $\cdot$ Migration

\section{INTRODUCTION}

At deep-sea hydrothermal vents, fluid flow changes, sulphide precipitation and episodic destruction of chimneys can create or remove surfaces within a few days (Fustec et al. 1987, Tunnicliffe \& Juniper 1990). New surfaces may be quickly colonised by macrofaunal species (Sarrazin et al. 1997, Tunnicliffe et al. 1997), and newly established animal communities may differ in species composition, density, biomass and, at the level of species, in size-structure, from communities already established in other parts of the smoker (Sarrazin et al. 1997, Sarrazin \& Juniper 1999). Then, these communities may undergo successional evolution and shift towards other communities as local physico-chemical conditions change and biological interactions develop (Sarrazin et al. 1997, 1999, Mullineaux et al. 2003). This dynamic generates patchiness 
at the decimetre scale and temporal variation at the sub-annual scale in animal communities that appears to be organised as a mosaic of patches at different stages of succession (Sarrazin et al. 1997, Sarrazin \& Juniper 1999).

On the East Pacific Rise (EPR), Alvinella pompejana Desbruyères et Laubier, 1980 is one of the first colonisers of new or reactivated hot chimney surfaces (Fustec et al. 1987, Gaill \& Hunt 1991, Chevaldonné 1996). While colonising new surfaces, alvinellids may locally modify flow patterns, fluid composition, mineral precipitation and the degree of hydrothermal mixing with seawater, therefore allowing establishment of other species exhibiting less tolerance to severe hydrothermal conditions (Juniper et al. 1992, Juniper \& Martineu 1995, Juniper \& Sarrazin 1995, Sarrazin \& Juniper 1999, Zbinden et al. 2003, Le Bris et al. 2005). Understanding the mechanisms and rates of arrival of $A$. pompejana at new patches is then important to elucidate mechanisms allowing the development of communities, and model the functioning of these mosaic systems.

Studies of mosaic communities from shallow-water or deep-sea environments have shown that disturbed or new patches may be colonised by several pathways: settlement of larvae from the water column, reproduction within or close to the patch by species with benthic development, or immigration of benthic juveniles or adults from adjacent areas (Santos \& Simon 1980, Levin 1984, Smith \& Brumsickle 1989, Shull 1997, Airoldi 2000). Whether colonists arrive as larvae, as juveniles, or adults may result in distinct communitydevelopment patterns (Sousa 2001). The relative importance of each of these pathways depends on the species life-history (seasonality in reproduction, development) (Levin 1984, Airoldi 2000), on the proximity of colonised patches (Sousa 1984), on the size of patches (Sousa 1984, Smith \& Brumsickle 1989), and on the timing of patch creation (Blanchette 1996).

Most vent species are sessile or have limited mobility as adults. Colonisation of new vents (i.e. patches isolated from occupied sites: Sousa 1985) probably occurs mostly through larval dispersal and recruitment (Lutz et al. 1984). However, when a new patch is created on an already colonised chimney (i.e. patch within occupied site: Sousa 1985), migration of juveniles or adults from neighbouring parts of the chimney might also contribute significantly to the colonisation of newlyopened surfaces (Gaill \& Hunt 1991, Chevaldonné \& Jollivet 1993, Tunnicliffe et al. 1993).

Larval recruitment implies that larvae are present in the water column or on another part of the chimney at the time of patch creation. For alvinellids, direct benthic development has been suggested (Desbruyères \& Laubier 1986, Zal et al. 1995). However, for Alvinella pompejana, experimental studies of its development rather suggest that embryos would develop away from adult colonies, and possibly undergo a dispersal phase (Pradillon et al. 2001). Reproductive mechanisms also remain poorly understood. Jollivet (1993) suggested that reproduction and recruitment in A. pompejana would be synchronous and annual at the vent scale. If this is the case, then larvae would be available for colonising new patches only during a restricted time period during the year.

This study investigated the colonisation mechanisms of newly opened patches by Alvinella pompejana, in an effort to determine how patch dynamics influence population structure and reproduction in this species. Because the early-life history of A. pompejana remains unsolved, we did no wish to make any assumption as to whether larvae would settle from the water column after a dispersal phase or would develop directly at the vent site. Therefore herein we consider 2 possible pathways of colonisation - larval recruitment or immigration of post-larval stages from adjacent areas. The null hypothesis was that colonisation of new habitat patches occurs mainly by short-distance migration of a representative subset of individuals from a background population (i.e. established patches). If this were the case, then the size- and stage-structure of colonists in new patches should resemble those in established patches, and sizes and reproductive maturity should not increase significantly with increasing patch age (Shull 1997). Alternatively, were the patch colonised by settlement of larvae or by migration of a nonrepresentative subset of the background population, patches opened at different times might be colonised by different cohorts, and differ in their age- and sizestructures (Levin 1984, Smith \& Brumsickle 1989). Specifically, our aims were to (1) test whether the ageand stage-structure of alvinellid colonists in new patches differs from those of the established population, (2) test whether the age- and stage-structure of colonists increases with increasing patch age, and (3) determine whether the age- and stage-structure of colonists are consistent with the migration of a representative subset of the background population, or with the migration of a non-representative subset, for instance through larval settlement.

\section{MATERIALS AND METHODS}

TRAC and grab collections. Alvinella pompejana were collected on a patch scale using a device called TRAC (Titanium Ring for Alvinellid Colonisation) that mimics a newly-opened surface at the $\mathrm{dm}^{2}$ scale when deployed on a vent structure (Gaill et al. 1996, Taylor et al. 1999). This device is made of $0.2 \mathrm{~cm}$ thick tita- 
nium sheets, shaped into tubes of $25 \mathrm{~cm}$ diameter and $15 \mathrm{~cm}$ height (Fig. 1a). Holes (0.8 cm in diameter) are drilled to permit vent-fluid circulation through the wall of the device, and internal rows serve as support for colonisation by alvinellid worms. Because TRACs tended to fall off the chimney when the deployment area was small or displayed strong relief, in 2 cases we used a smaller version $(15 \mathrm{~cm}$ in diameter, and $10 \mathrm{~cm}$ in height) (Fig. 1b).

TRACs vere deployed for durations from $11 \mathrm{~d}$ up to 5 mo (see Table 1). As it is extremely difficult to conduct manipulative ecological studies in a high temperature environment, we included all suitable samples, even those that were not part of the optimal sampling design. Herein we present data on 9 colonisation experiments; these were part of a set of 16 deployments (T1 to T16) of TRACs, 7 of which collected no A. pompejana. The deployments were conducted between 1995 and 1999, at vents near $9^{\circ} 50^{\prime} \mathrm{N}, 104^{\circ} 17^{\prime} \mathrm{W}$ and $12^{\circ} 48$ to $49^{\prime} \mathrm{N}, 103^{\circ} 56^{\prime} \mathrm{W}$ along the EPR (see also Table 1, Fig. 2) at water depths of 2500 and $2600 \mathrm{~m}$ respectively. Deployments and recoveries of TRACs were conducted with the manned submersibles 'Alvin' or 'Nautile'. Upon recovery, while still on the seafloor the TRACs were placed in a box, which was closed to avoid losses during ascent to the surface.

To minimise the range of thermal and chemical conditions to which the TRACs were exposed, we attempted to position them in locations where temperatures were around $40^{\circ} \mathrm{C}$. Temperatures were recorded on deployment, recovery and at intermediate dates, using temperature probes positioned by the submersible manipulator at several locations on the TRAC (Fig. 1a) to take into account centimetre-scale variation (Chevaldonné et al. 1991, Sarradin et al. 1998, Sarrazin et al. 1999, Le Bris et al. 2005). TRAC 13 (T13), T14 and T16 were each equipped with HOBO temperature probes (Fig. 1b) that allowed semicontinuous recordings for $1 \mathrm{wk}, 2 \mathrm{wk}$ and the whole duration of the
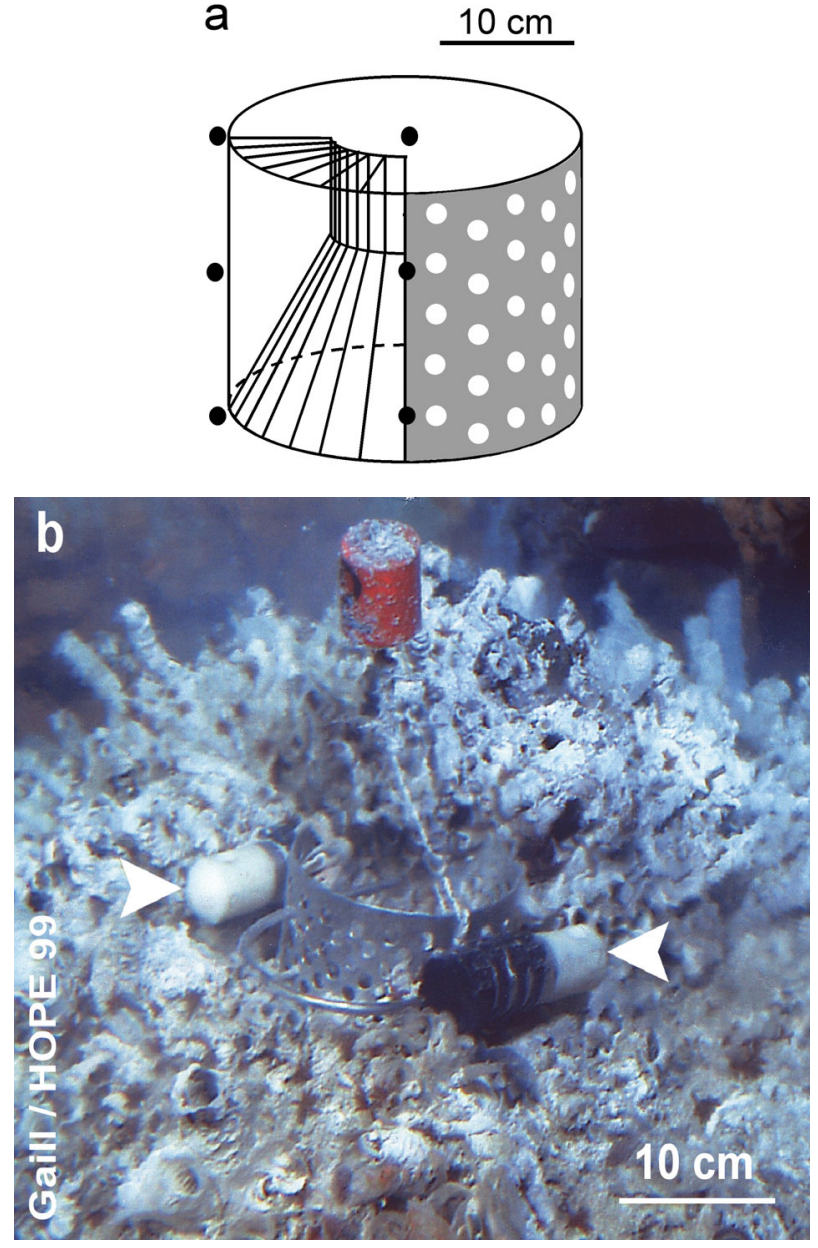

Fig. 1. Colonisation experiments. (a) TRAC (titanium ring for alvinellid colonisation) device, showing locations of temperature measurements $(\bullet)$; for clarity, internal and external structures are shown separately, each for one-quarter of device: front left part shows structure of internal rows that serve as support for colonisation; front right part shows outside wall containing holes allowing fluid circulation. (b) TRAC (T14) deployed on alvinellid colony at Grandbonum, $13^{\circ} \mathrm{N}$.

Arrowheads show temperature probes fastened to TRAC

Table 1. Experimental settings of TRAC deployments (T) with demographic and reproductive features of Alvinella pompejana collected. Temperature data were used to rank TRACs by general thermal environment. $++:>40^{\circ} \mathrm{C}_{i}+:>15^{\circ} \mathrm{C}_{i}-:<10^{\circ} \mathrm{C}$. Male:female ratios were tested for 50:50 distribution using chi-square with significance level of $\mathrm{p}<0.05$ (in parentheses). *'Smaller TRAC used (see 'Materials and methods'); IRST = in situ residence time; S4: 4th setigerous segment; nd: no data

\begin{tabular}{|c|c|c|c|c|c|c|c|c|c|c|}
\hline No. & $\begin{array}{l}\text { Deployment } \\
\text { site }\end{array}$ & $\begin{array}{l}\text { Deployment } \\
\text { date }\end{array}$ & $\begin{array}{l}\text { ISRT } \\
\text { (d) }\end{array}$ & $\begin{array}{c}\text { Thermal } \\
\text { environment }\end{array}$ & $\begin{array}{l}\text { No. of } \\
\text { ind. }\end{array}$ & $\begin{array}{c}\text { No. of } \\
\text { females }\end{array}$ & Male:female & $\begin{array}{l}\text { S4 width } \\
\text { (mm) }\end{array}$ & $\begin{array}{r}\text { No. } \\
\text { Mature }\end{array}$ & $\begin{array}{l}\text { females } \\
\text { Reproductive }\end{array}$ \\
\hline T3 & $\mathrm{M}$ Vent, $9^{\circ} \mathrm{N}$ & Dec 18, 1995 & 70 & ++ & 66 & 36 & $0.75(\mathrm{~ns})$ & $1.1-7.9$ & 13 & 7 \\
\hline T5 & $\mathrm{M}$ Vent, $9^{\circ} \mathrm{N}$ & Nov 30, 1997 & 11 & + & 11 & 5 & 1 (ns) & $2.9-5.9$ & 0 & 0 \\
\hline $\mathrm{T} 6$ & $\mathrm{M}$ Vent, $9^{\circ} \mathrm{N}$ & Dec 13, 1997 & 155 & - & 2 & 0 & nd & $2.1-3.9$ & nd & nd \\
\hline T9 & Q Vent, $9^{\circ} \mathrm{N}$ & Nov 28, 1998 & 150 & ++ & 15 & 7 & $1.14(\mathrm{~ns})$ & $3.5-9.2$ & 6 & 5 \\
\hline $\mathrm{T} 10$ & M Vent, $9^{\circ} \mathrm{N}$ & Dec 6, 1998 & 139 & ++ & 8 & 2 & 3 (ns) & $4.1-7.2$ & 1 & 1 \\
\hline T11 & M Vent, $9^{\circ} \mathrm{N}$ & Apr 27, 1999 & 11 & + & 4 & 1 & 2 (ns) & $1.5-5.9$ & 0 & 0 \\
\hline $\mathrm{T} 13^{*}$ & Genesis, $13^{\circ} \mathrm{N}$ & May 1, 1999 & 16 & ++ & 93 & 41 & $1.17(\mathrm{~ns})$ & $0.5-6.8$ & 1 & 0 \\
\hline $\mathrm{T} 14^{*}$ & Grandbonum, $13^{\circ} \mathrm{N}$ & May 2, 1999 & 26 & + & 17 & 11 & $0.45(\mathrm{~ns})$ & $1-7.8$ & 3 & 0 \\
\hline T16 & Pulsar, $13^{\circ} \mathrm{N}$ & May 13, 1999 & 19 & ++ & 17 & 7 & 1.43 (ns) & $1.4-12.7$ & 5 & 0 \\
\hline
\end{tabular}




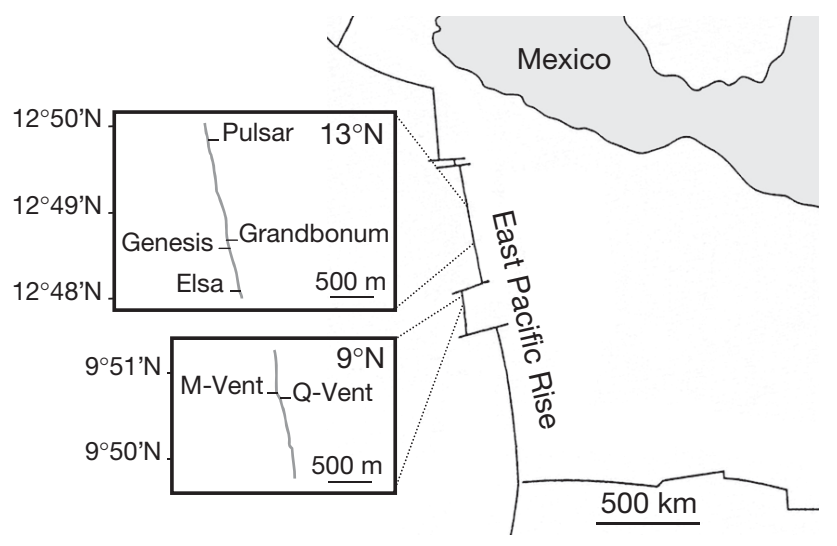

Fig. 2. Vent sites on $9^{\circ} \mathrm{N}$ and $13^{\circ} \mathrm{N}$ segments of East Pacific Rise where TRAC colonisation experiments were conducted

deployment respectively. During in situ residence time, chemical, mineral precipitation and temperature conditions often changed, sometimes drastically. Herein we use the temperature data available to rank the TRACs by general thermal environment, and to evaluate whether environmental conditions changed during the experiment (see Table 1).

Alvinella pompejana background populations were obtained by sampling with the submersible's claw among established population on the chimney wall at $13^{\circ} \mathrm{N}$ sites in May 1999 (see Table 2). Each grab collection comprised several grabs taken from a small area of the chimney $(\sim 50 \times 50 \mathrm{~cm}$ covering several adjacent patches). Pooling several adjacent grabs into a single sample allowed us to increase the number of $A$. pompejana in each sample. In addition, the limited number of collection boxes that could be placed in the submersible basket during each dive did not allow us to maintain each grab separately.

On-board preservation. After recovery and ascent to the surface, colonised TRACs were dissected from the top to the base. Alvinella pompejana specimens in TRACs and grab samples were separated from their tubes, minerals or other species. All residues and small particles resulting from the sorting process were conserved to search for small individuals or larvae. Specimens were fixed with $3.7 \%$ neutral formalin in sea water, preserved in $70 \%$ ethanol, and stored in vials.

Size and reproductive maturity. Sex was determined externally by the morphology of the genital pore (Pradillon \& Gaill 2003), or by the presence, in males, of 1 pair of thick buccal tentacles, which are lacking in females (Desbruyères et al. 1998).

After preservation and prior to dissection, the width of the 4th setigerous segment (S4) of each individual was measured with a digital caliper of 0 to $200 \mathrm{~mm}$ (error due to positioning of the caliper on the S4 segment: $0.10 \mathrm{~mm}$ ). S4 width was preferred as an index of individual size because it correlates well with individual dry weight (Jollivet 1993). For each female, we carefully collected coelomic fluid by making a small incision ventrally in the body wall of the trunk to release the fluid (Olive 1970). Specimens were then cut open along the anterior-posterior axis, from S1 to the posterior end of the body. The body cavity was washed extensively in order to collect all coelomic oocytes. The genital tract, including both oviducts and spermathecae, was then carefully dissected.

We used 2 parameters to determine reproductive maturity in females: (1) the presence/absence of oocytes, and (2) in females lacking oocytes, the size and shape of the oviducts. When packed with oocytes, oviducts were long and distended (oviduct length:S4 width ratio between 1.70 and 2.40), whereas they were relatively thin and short were empty (oviduct length:S4 width ratio $<1$ ). However, in some females without oocytes, oviducts were nevertheless quite long (oviduct length:S4 width ratio between 1.40 and 1.70) with obvious wall distension: in such cases, we assumed that the oviducts had previously been packed with oocytes, and had retained their distended shape. Accordingly, females were sorted as juvenile (short oviducts and no oocytes), or mature (distended oviducts and/or with oocytes). Mature females with oocytes were regarded as reproductive females.

Table 2. Alvinella pompejana. Demographic and reproductive features in grab (G) samples. Male:female ratios were tested for 50:50 distribution using chi-square with significance level of $\mathrm{p}<0.05$ (in parentheses)

\begin{tabular}{|c|c|c|c|c|c|c|c|c|}
\hline No. & $\begin{array}{l}\text { Collection } \\
\text { site }\end{array}$ & $\begin{array}{l}\text { Collection } \\
\text { date (1999) }\end{array}$ & $\begin{array}{c}\text { No. of } \\
\text { individuals }\end{array}$ & $\begin{array}{c}\text { No. of } \\
\text { females }\end{array}$ & Male:female & $\begin{array}{l}\text { S4 width } \\
\text { (mm) }\end{array}$ & $\begin{array}{r}\text { No. } \\
\text { Mature }\end{array}$ & $\begin{array}{l}\text { of females } \\
\text { Reproductive }\end{array}$ \\
\hline G1 & Elsa PP50, $13^{\circ} \mathrm{N}$ & May 19 & 28 & 19 & 0.47 (ns) & $3.3-8.3$ & 7 & 2 \\
\hline G2 & Grandbonum, $13^{\circ} \mathrm{N}$ & May 20 & 72 & 38 & 0.89 (ns) & $1.7-9.3$ & 10 & 2 \\
\hline G3 & $\mathrm{M}$ Vent, $9^{\circ} \mathrm{N}$ & May 9 & 8 & 6 & $0.33(\mathrm{~ns})$ & $4.3-11.2$ & 5 & 3 \\
\hline G4 & Elsa HOT $14,13^{\circ} \mathrm{N}$ & May 15 & 54 & 24 & $1.21(\mathrm{~ns})$ & $2.1-9.2$ & 10 & 3 \\
\hline G5 & Genesis, $13^{\circ} \mathrm{N}$ & May 16 & 3 & 1 & - & $2.7-7.3$ & 1 & 1 \\
\hline G6 & $\mathrm{M}$ Vent, $9^{\circ} \mathrm{N}$ & May 8 & 16 & 10 & $0.6(\mathrm{~ns})$ & $3.7-8$ & $5^{\mathrm{a}}$ & $5^{\mathrm{a}}$ \\
\hline G7 & Pulsar, $13^{\circ} \mathrm{N}$ & May 13 & 4 & 1 & 3 (ns) & $2.3-7.1$ & 1 & 0 \\
\hline
\end{tabular}


Oocyte counts and measurements. Oocytes of all reproductive females from TRACs were counted and measured. In grab samples, oocytes of several reproductive females were used for other studies (development), and were not available here. Therefore, grab samples were not used here for statistical comparisons of oocyte size frequency distribution.

Oocytes collected from the coelomic cavity were resuspended in $70 \%$ ethanol. Oocytes from 3 aliquots of identical volumes representing 1 to $10 \%$ of the total suspension were counted and measured. In oviducts, we estimated oocyte number by counting oocytes of 1 of the 2 oviducts. If the oviduct analysed contained less than 500 oocytes or if both oviducts did not appear equally filled, we counted all oocytes from both oviducts. All oocytes found in the spermathecae were counted and measured.

Oocytes were measured using an eye-piece micrometer under a Zeiss Stemi SV11 binocular microscope. Because of their flat spherical shape, we measured their largest diameter (hereafter 'diameter' unless specified otherwise). Oocytes from the coelomic cavity are almost twice as flat as those from the genital tract (Pradillon \& Gaill 2003). Therefore, to enable us to pool data from all oocytes when analysing their sizefrequency distribution, we used their equivalent diameter (i.e. diameter of a sphere of the same volume), calculated as $2\left(R^{3} / f\right)^{1 / 3}$, where $R$ is the large radius, and $f$ is the degree of flatness (diameter $\div$ thickness), using $f=1.7$ and 3 for oviduct and coelomic oocytes respectively (Pradillon \& Gaill 2003).

Statistical analysis. Statistical analyses were conducted with Microsoft Excel 98 and SYSTAT 10.2 softwares. Chi-square tests were performed to analyse sex ratios. Oocytes and S4 width size-frequency distribution were tested for normality using the KolmogorovSmirnov test. Effect of sex, patch-type (TRAC or grab), and segment $\left(9^{\circ} \mathrm{N}\right.$ or $\left.13^{\circ} \mathrm{N}\right)$ on specimen average size in each sample was tested using 3-way ANOVA; 1-way ANOVA and post-hoc multi-sample Tukey tests were performed to identify samples with no significant differences in the average size of individuals. Samples with fewer than 2 individual, and small Alvinella pompejana that we could not identify sex were not taken into account for these analyses. Effect of patch-type and segment on the percentage of mature females and reproductive females within the different collections were tested using a MANOVA. Percentage data were arcsine-transformed before performing statistical tests (Sokal \& Rohlf 1995). In grab samples, 3 large females from grab sample 6 (G6) were not available for maturity analysis and are only included in the size analysis.

Homogeneity between oocyte size-frequency distributions was tested using Kruskal-Wallis multi-sample tests, and post-hoc multi-sample tests using Dunn probabilities were performed to assess the degree of synchrony in oocyte development.

Correlations between the percentage of mature females, the percentage of reproductive females, in situ residence time of TRAC, and mean size of females were assessed using Spearman's rank correlation coefficient $\left(r_{\mathrm{S}}\right)$.

\section{RESULTS}

\section{Colonisation experiments}

Of 16 TRAC deployments, 9 revealed colonisation by Alvinella pompejana (Table 1) and other vent species (M. Zbinden et al. unpubl. data). Among the 7 deployments recovered without $A$. pompejana, 1 had become too embedded in mineral precipitation during its in situ residence time to be recovered, 2 were colonised by vent fauna other than alvinellids, and 4 were not colonised-either because we used a TRAC device without holes (the resultant lack of fluid circulation may have prevented colonisation processes), or because the TRAC fell from its deployment site at the fluid vent during the experiment. We found a few Alvinella sp. tubes on the 2 TRACs colonised by vent fauna other than alvinellids, suggesting that $A$. pompejana or the other alvinellid tube-building species, $A$. caudata, had colonised the devices at some time during the experiments. Temperature around these 2 TRACs was slightly above abyssal temperature $\left(\sim 3^{\circ} \mathrm{C}\right)$ indicating that TRACS were out of fluid venting. This change in environmental conditions probably caused Alvinella to leave their tubes because the habitat no longer offered suitable conditions.

\section{Size structure}

Alvinella pompejana colonisation on our 9 TRAC deployments was highly variable, ranging from 2 to 93 individuals (Table 1). In each experiment, the male:female ratio was not significantly different from a 50:50 distribution (Table 1). In grab samples, we also collected a highly variable number of individuals (3 to 72 ) and sex ratios were in equilibrium (Table 2).

Individuals were present over a large range of sizes in both TRAC (0.5 to $12.7 \mathrm{~mm} \mathrm{S4}$ ) and grab samples (1.7 to $11.2 \mathrm{~mm} \mathrm{S4}$ ) (Tables 1 \& 2). We did not find benthic larval stages such as those described for the alvinellid species Paralvinella pandorea irlandei (Desbruyères \& Laubier 1986); all individuals were postlarval stages (juveniles or adults).

We used a 3-way ANOVA to compare the average size of Alvinella pompejana between TRAC and grab 
Table 3. Alvinella pompejana. Three-way ANOVA comparing average size between TRAC and grab samples (Patch-type), among $9^{\circ} \mathrm{N}$ and $13^{\circ} \mathrm{N}$ samples (factor Ridge segment nested in Patch-type), and between sexes.

SS: sum of squares; MS: mean squares; significance level is $\mathrm{p}<0.05$

\begin{tabular}{|lrrrrc|}
\hline Source & SS & df & MS & F-ratio & p \\
\hline Patch-type & 6.563 & 1 & 6.563 & 4.136 & 0.055 \\
Sex & 0.025 & 1 & 0.025 & 0.016 & 0.901 \\
Sex $\times$ Patch-type & 2.660 & 1 & 2.660 & 1.676 & 0.210 \\
Segment (Patch-type) & 3.398 & 2 & 1.699 & 1.071 & 0.362 \\
Sex $\times$ Ridge segment (Patch-type) & 0.512 & 2 & 0.261 & 0.164 & 0.850 \\
Error & 31.734 & 20 & 1.587 & & \\
\hline
\end{tabular}

significant, ns) (Fig. 4). However, Fig. 4 shows T16 as an outlier; when it is removed from the analysis, the average size of A. pompejana does correlate positively and significantly with in situ residence time $\left(r_{\mathrm{S}}=0.793, \mathrm{p}<0.05\right)$.

\section{Reproductive maturity in females}

In both the TRAC and grab samples, mature females were found only in size classes >5 mm S4 (Fig. 5a). Among mature samples and, at the same time, to check whether geographic location (ridge segment) or sex might have biased the sampling design. The 3-way ANOVA revealed that patch-type (TRAC versus grab sample), segment $\left(9^{\circ} \mathrm{N}\right.$ versus $\left.13^{\circ} \mathrm{N}\right)$ and sex had no significant effect on the average size of A. pompejana (Table 3, Fig. 3). However, despite not being significant, the p-value for patch-type was very low (Table 3), and Fig. 4 shows that $A$. pompejana in TRACs tend to be smaller than those in grab samples.

When individual TRACs were compared, ANOVA revealed that the sizes of Alvinella pompejana colonising each of them were significantly different ( $p<0.001)$. A pairwise Tukey's test showed that individuals in TRACs T6 and T13 were significantly smaller than those in T3, T9, T10 and T16, whereas individuals in T16 were significantly larger than those in T3, T5, T6, T11, T13 and T14. This pattern did not reflect the different ridge segments in which the TRACs were deployed, nor the general thermal environment of the individual TRACs. We found no correlation between in situ residence time and the average size of $A$. pompejana of the TRACs $\left(r_{\mathrm{S}}=0.599\right.$, not

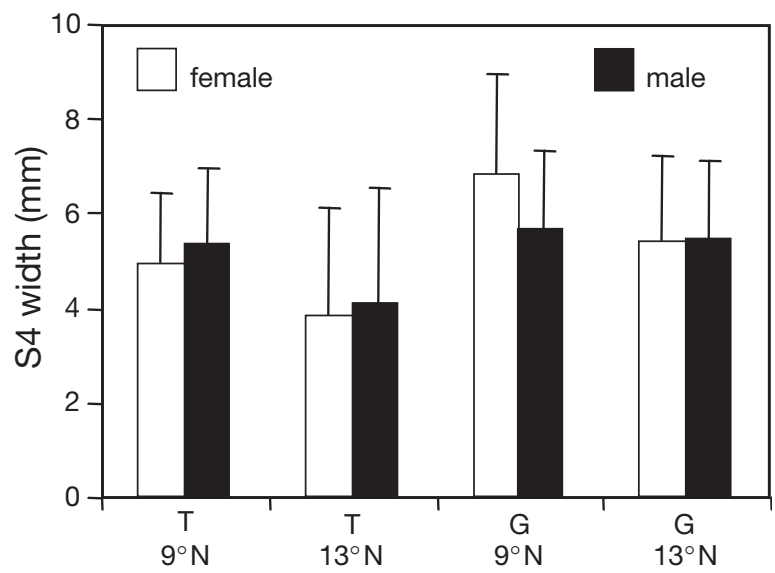

Fig. 3. Alvinella pompejana. Average $(+1 \mathrm{SD})$ size of males and females in TRAC (T) and grab (G) samples collected at $9^{\circ} \mathrm{N}$ or $13^{\circ} \mathrm{N}$. S4: 4 th setigerous segment females, the size distributions of reproductive and nonreproductive females completely overlapped (Fig. 5b). Thus, in Alvinella pompejana, sexual maturity can be expected when females reach $40 \%$ of their maximum size (the largest female encountered in all samples was $12.7 \mathrm{~mm}$ S4). However, reproductive activity (actual gamete production) cannot be predicted from the size of a female. This was confirmed by our TRAC and grab samples, where there was a positive correlation between the percentage of mature females and mean female size $\left(r_{\mathrm{S}}=0.766, \mathrm{p}<0.05\right)$, whereas the percentage of reproductive females did not correlate with mean female size $\left(r_{\mathrm{S}}=0.518, \mathrm{~ns}\right)$. Fecundity was highly variable, from a few hundred to 137500 oocytes per female. Highest fecundity was recorded in a female of $6.1 \mathrm{~mm}$ S4 width. Fecundity, and mean diameter of oviduct and coelomic oocytes were not correlated with the individual size of reproductive females (for size versus total oocyte number $r_{\mathrm{S}}=0.070, \mathrm{~ns}$; for size versus mean diameter of oviduct oocytes $r_{\mathrm{S}}=0.545, \mathrm{~ns}$; for size versus mean diameter of coelomic oocytes $r_{\mathrm{S}}=$ $0.021, \mathrm{~ns})$.

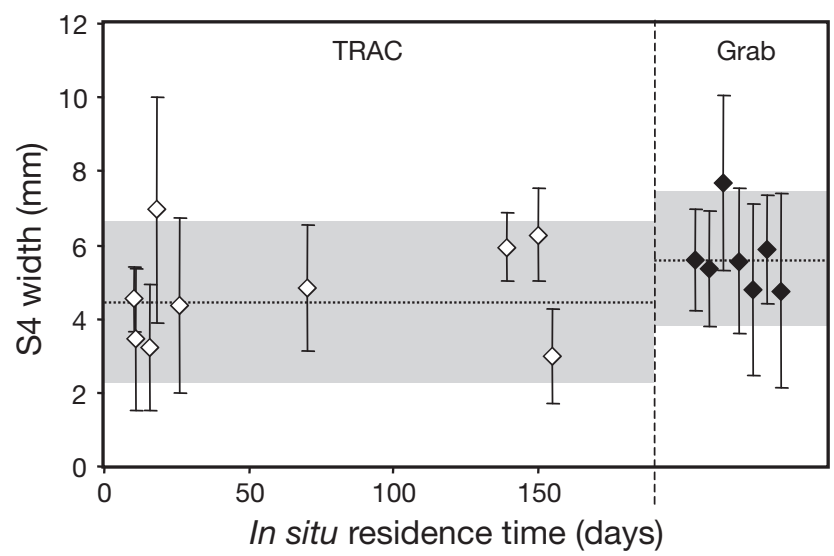

Fig. 4. Alvinella pompejana. Average $( \pm \mathrm{SD})$ size in TRACs as a function of in situ residence time, and in grab samples. Dotted horizontal lines indicate average size of individuals pooled from all TRAC or all grab samples, and shaded area represents standard deviation of pooled data 

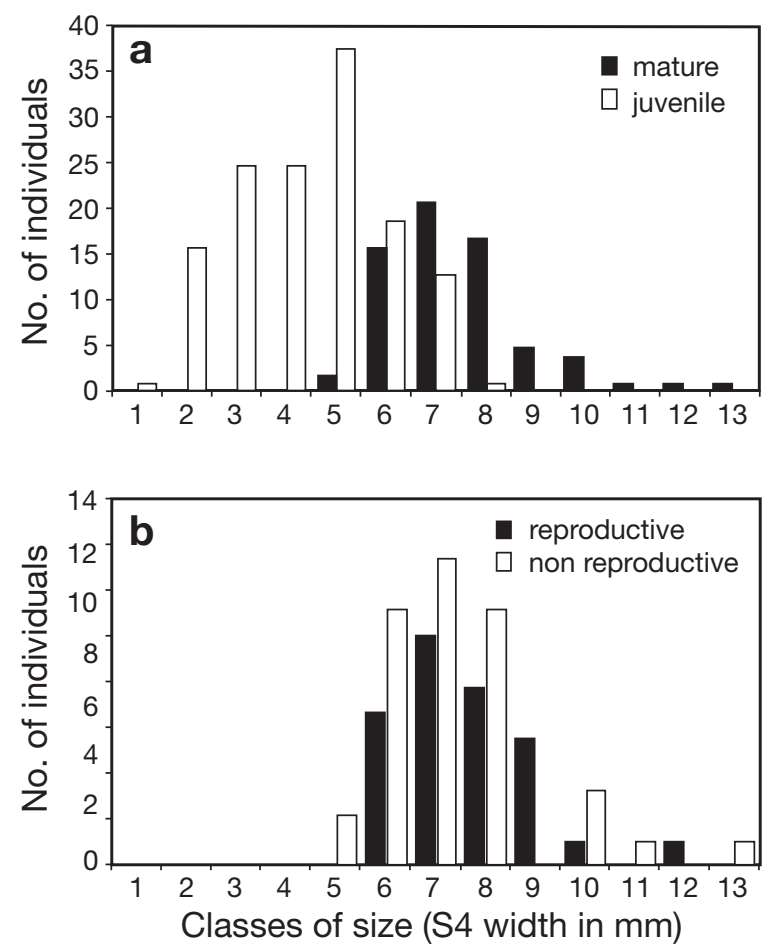

Fig. 5. Alvinella pompejana. Size distribution of females at different reproductive stages. (a) Juveniles and mature females; (b) reproductive and non-reproductive individuals of the mature females. Data for all females from TRACs and grabs pooled

The percentage of mature and reproductive specimens among females varied widely from 0 to $86 \%$ and from 0 to $71 \%$ respectively (Patches T11, G5 and G7 not considered here because they contained only 1 female each) (Tables 1 \& 2). A 2-way MANOVA detected no significant effect of patch-type and ridge segment on the percentages of mature and reproductive specimens among females (Table 4).

The percentage of mature females as well as the percentage of reproductive females correlated positively and significantly with in situ residence time of TRACs $\left(r_{\mathrm{S}}=0.855, \mathrm{p}<0.02 ; r_{\mathrm{S}}=0.878, \mathrm{p}<0.02\right.$ respectively $)$.
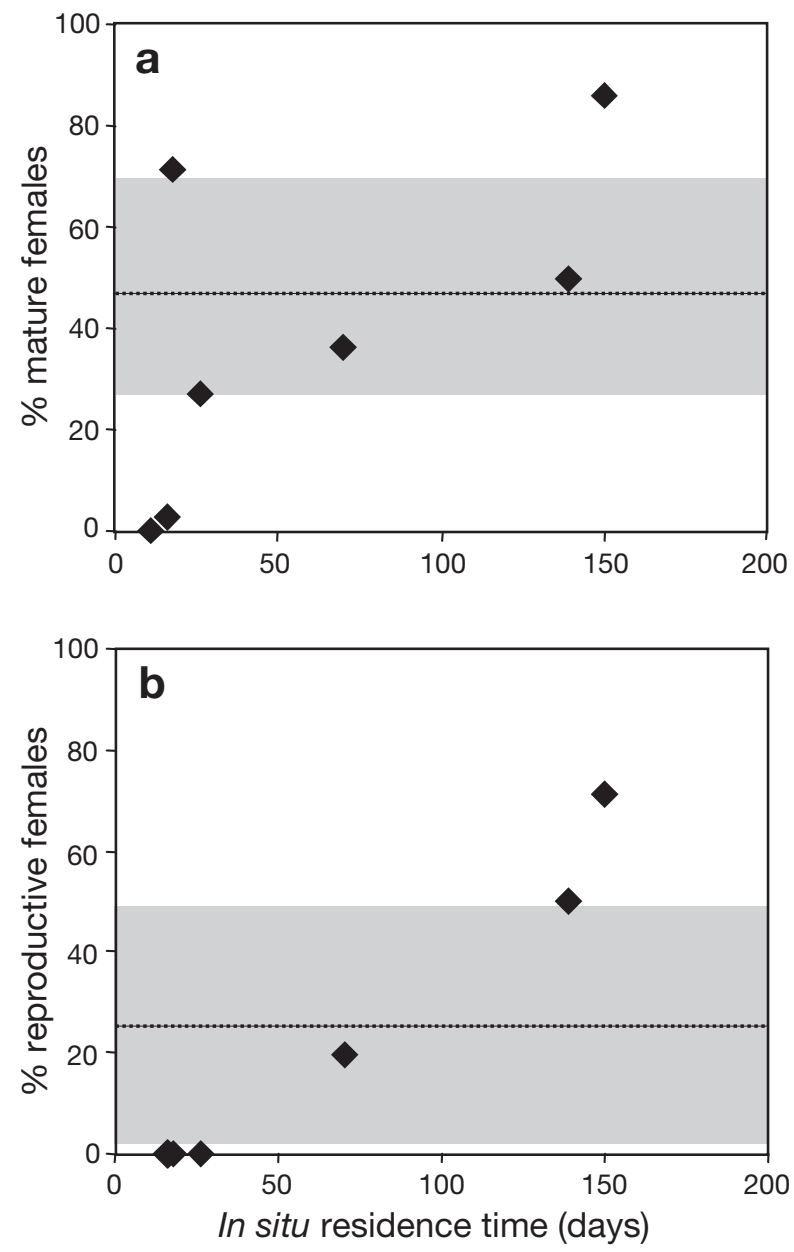

Fig. 6. Alvinella pompejana. Percentage of (a) mature and (b) reproductive females in TRAC as a function of in situ residence time. Dotted lines indicate the average percentage of mature and reproductive females in grab samples, and shaded area represents standard deviation

The percentage of reproductive females increased monotonically with residence time (Fig. 6b), whereas the percentage of mature females had 1 outlier (T16) (Fig. 6a). This was related to the large average size of individuals in this experiment.

Table 4. Alvinella pompejana. MANOVA comparing percentage reproductive females and percentage mature females between TRAC and grab samples (Patch-type), and between $9^{\circ} \mathrm{N}$ and $13^{\circ} \mathrm{N}$ (Ridge segment)

\begin{tabular}{|c|c|c|c|c|c|c|c|c|c|c|c|}
\hline \multirow[t]{3}{*}{ Source } & \multicolumn{8}{|c|}{$\longrightarrow$ Univariate ANOVAs } & \multirow{2}{*}{\multicolumn{3}{|c|}{ MANOVA }} \\
\hline & \multicolumn{4}{|c|}{$\%$ reproductive females } & \multicolumn{4}{|c|}{$\%$ mature females } & & & \\
\hline & df & MS & $F$ & $\mathrm{p}$ & $\mathrm{df}$ & MS & $F$ & $\mathrm{p}$ & Wilks' $\lambda$ & $F$ & $\mathrm{p}$ \\
\hline Patch-type & 1 & 0.526 & 2.297 & 0.158 & 1 & 0.194 & 0.627 & 0.445 & 0.797 & 1.277 & 0.321 \\
\hline Ridge segment & 1 & 0.475 & 2.071 & 0.178 & 1 & 0.075 & 0.243 & 0.587 & 0.830 & 1.022 & 0.395 \\
\hline Patch-type $\times$ ridge segment & 1 & 0.030 & 0.130 & 0.725 & 1 & 0.049 & 0.159 & 0.698 & 0.973 & 0.138 & 0.872 \\
\hline Error & 11 & 0.229 & & & 11 & 0.309 & & & & & \\
\hline
\end{tabular}




\section{Reproductive within-patch synchrony}

Given the relatively small number of reproductive females found in our samples, we focused only on those with a sufficient number of individuals to allow comparison, and conducted our analysis on the scale of individual patches, namely T3 and T9. The oocyte sizefrequency distribution of individual Alvinella pompejana differed significantly from normal (KolmogorovSmirnov normality test, $\mathrm{p}<0.05)$, and typically comprised a wide range of oocyte size (15 to $140 \mu \mathrm{m}$ equivalent diameter), with a peak in the frequency of smaller oocytes (between 20 and $40 \mu \mathrm{m}$ equivalent diameter) (Fig. 7). For some females a second peak also appeared between 100 and $120 \mu$ m equivalent diameter.

For TRAC T3, the 7 reproductive females showed significant differences in oocyte size distribution (Kruskal-Wallis multi-sample test, $H=42.9$, p $<0.001$, $6 \mathrm{df})$. Multiple comparison tests using Dunn's method showed that 5 females had homogeneous oocyte distribution ( $38 \%$ of the mature females). In TRAC T9, the 5 reproductive females showed significant differences in the oocyte size distribution of individuals within the sample (Kruskal-Wallis multi-sample test, $H=264.9$,
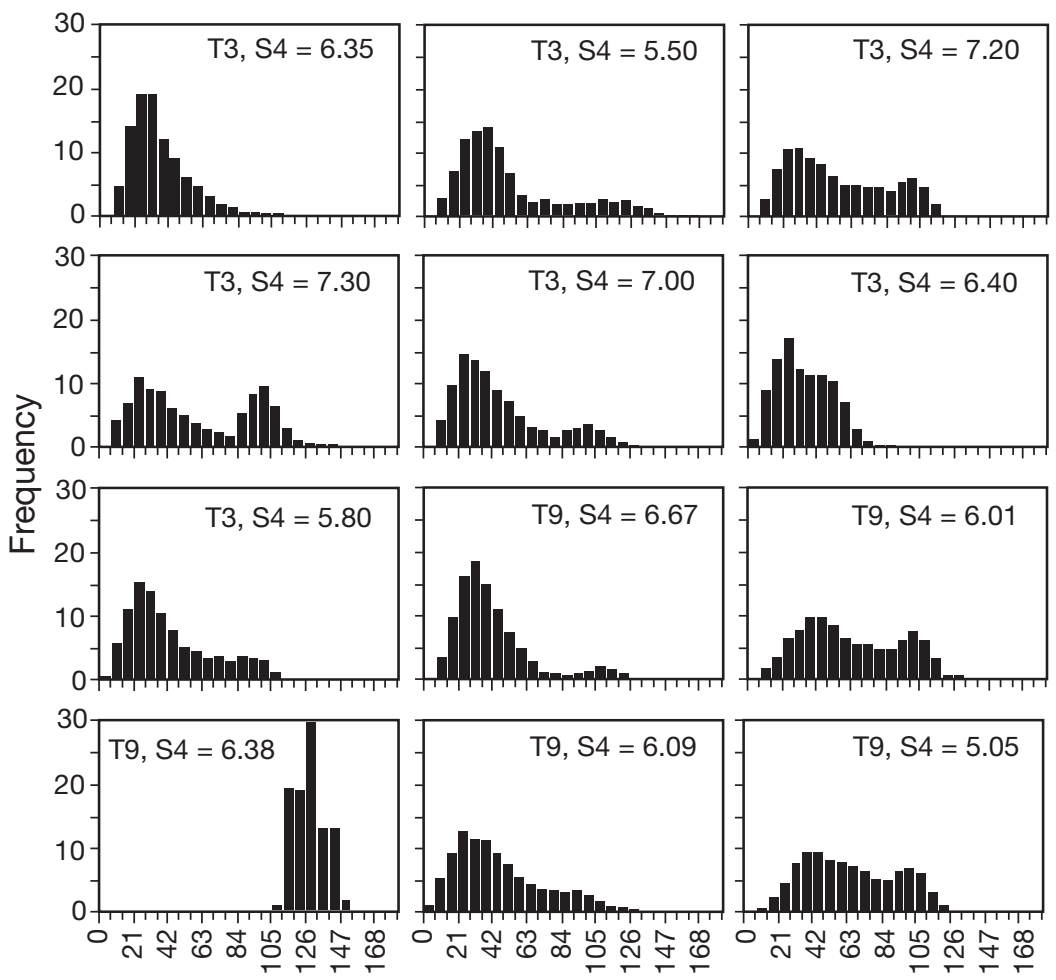

Equivalent diameter $(\mu \mathrm{m})$

Fig. 7. Alvinella pompejana. Size-frequency distribution of equivalent diameter of oocytes for females from TRACs 3 and 9 (T3, T9). Histograms plotted using size-class intervals of $7 \mu \mathrm{m}$ and smoothed using weighted moving average of third order. S4 width of each female is indicated $\mathrm{p}<0.001,4 \mathrm{df})$. Multiple comparison tests using Dunn's method showed that 3 of these were homogeneous for oocyte distribution (42\% of mature females).

\section{DISCUSSION}

Alvinella pompejana is a pioneer species in the colonisation of new or reactivated sulphide surfaces at hydrothermal vents, and may have an important role in the establishment of other species and the development of animal communities. Colonisation rates of new patches may result from the coincidence between the timing of disturbance (sulphide accretion that creates new mineral surfaces), and the timing of colonist availability. The timing of disturbance is not predictable, but mineral precipitations can create new surfaces within a few days (Tunnicliffe et al. 1993), and such episodes might occur several times per year at active sites (Sarrazin et al. 1997). The timing of colonist availability depends on the life-history stage at which organisms will colonise the new patch. In marine communities, colonisation by post-larval stages (juveniles or adults) migrating from the vicinity might occur within a few days at any time of the year (Levin 1984, Smith et al. 1986, Smith \& Brumsickle 1989, Kukert \& Smith 1992). Conversely, recruitment of larvae might be influenced by the location of the disturbance (e.g. proximity of a source of propagules, i.e. reproductive adults) and/or seasonality in reproduction, and therefore be much more variable over the year (Dethier 1984, Levin 1984, Blanchette 1996).

To evaluate whether colonisation might have been achieved by recruitment of larvae or by immigration of juveniles or adults, data on the size at recruitment and on growth rates are necessary (Shull 1997). Such data are not currently available for Alvinella pompejana. Nevertheless, the fast colonisation times (11 d for the shortest interval leading to colonisation by A. pompejana), and large sizes of some individuals in short-term experiments (Table 1) indicate that most of the colonists were probably juveniles and adults migrating from adjacent areas of the smoker. Some very small individuals may also have recruited as larvae onto the TRACs.

The size of Alvinella pompejana was slightly but not significantly larger in background samples (grab) than in the TRACs, and there was a slight but not sig- 
nificant increase in individual mean size with increasing deployment interval in the TRACs. However, our analysis showed 1 outlier (Patch T16), and once this had been removed both trends became significant. T16 was colonised by very large individuals (outlier in Fig. 4) compared to other TRACs deployed for similar periods $(<1 \mathrm{mo})$. It had been deployed on an active black smoker. Black smokers usually harbour older alvinellid populations with larger individuals than white smokers (Chevaldonné \& Jollivet 1993). Although the temperature recorded around T16 were comparable to the thermal environment recorded around other TRACs (Table 1), this sample may not be comparable to the other samples, since the alvinellid population on which it was deployed was older than those in the other experiments.

Reproductive adults were collected in our TRAC colonisation experiments as well as in background samples; however, in TRACs, they were restricted to long term deployments ( $>1 \mathrm{mo}$ ). Although the sampling design incorporated samples from different regions and deployments at different times, there is no evidence that these factors were responsible for the patterns observed. All TRACs with short-term deployment intervals lacked reproductive females, whatever their deployment site or recovery date. In addition, grab samples collected in May 1999, when most short-term TRACs were also recovered, did have reproductive females, suggesting that the absence of reproductive females on TRAC deployed for short periods was not due to seasonality in reproduction.

The absence of developing gametes from short-term TRAC deployments might imply either (1) that none of the individuals had reached the age at which time gametogenesis would be observed, or (2) that they had recently completed gametes spawning. The first hypothesis fits well with Patches T5, T11 and T13, where almost all females were smaller than the critical size for sexual maturity. In these cases, colonisers were juveniles. TRACs T14 and T16 would better fit the second scenario, because many females were mature, and several large Alvinella pompejana exhibited distended oviducts, suggesting that these females had recently spawned. This indicates that migrants to new patches are not only juveniles but also comprise a subset of pre-reproductive females from the background population, but not reproductive females. Smith \& Brumsickle (1989) similarly observed that brooding females of the polychaete tube dweller Streblospio benedicti from intertidal sediments were less likely to disperse than other stages. Migration of juveniles into new patches has also been evidenced for different intertidal and deep-sea communities (Smith \& Hessler 1987, Smith \& Brumsickle 1989).
Why would reproductive females be less likely to migrate than other stages? Space and access to fluid flow are limiting resources for vent animals, and when habitat expansion occurs through sulphide accretion, competition in animal assemblages may be attenuated, as some individuals migrate into new spaces (Tunnicliffe \& Juniper 1990, Sarrazin et al. 1997). These individuals that cannot find sufficient resources will be the most likely to seek a new habitat where such resources are available. Reproductive individuals that are able to sustain energetically expensive egg production (Ramirez Llodra 2002) are presumably not limited in resource availability, and therefore not 'constrained' to migrate elsewhere. In addition, in Alvinella spp., migration is thought to occur by means of tube secretion along the chimney wall (Gaill \& Hunt 1991, Chevaldonné \& Jollivet 1993). Tube production may involve a large energy investment for each individual, as tube production rates calculated for short deployments showed that worms could produce up to $40 \%$ of their own tube weight daily (M. Zbinden et al. unpubl. data). Because of resource limitation, females might not be able to simultaneously sustain tube secretion for migration processes and gamete production.

One of our initial goals was to assess the question of synchrony in reproduction of Alvinella pompejana. Previous studies suggested that recruitment of larvae and reproduction would be discontinuous and synchronised at the vent scale (Jollivet 1993). Here, on the scale of single patches, we found a mixture of mature females that had already spawned and reproductive females with heterogenous size-frequency distributions of oocytes. Although we admit the small number of reproductive females in our samples, these results indicate that reproduction would be asynchronous at the patch scale. In the alvinellid family, asynchronous reproduction was also suggested for Paralvinella sulfincola (Copley 1998) and P. pandorae (McHugh 1989). In contrast, $P$. grasslei (Zal et al. 1995) and P. palmiformis (Copley et al. 2003) were suggested to reproduce synchronously at the vent scale, responding to periodic variation linked to a tidal regime in environmental factors such as temperature (Chevaldonné et al. 1991, Johnson et al. 1994). In P. palmiformis, however, spatial variation in reproductive patterns was found at the vent scale, perhaps reflecting a successional mosaic of the vent community, with immature individuals in earlier successional stages (Copley et al. 2003). In A. pompejana, the dynamic disturbance/ colonisation process might similarly result in a mosaic of patches harbouring individuals at different reproductive stages (Fig. 8). New surfaces are colonised within a few days by juveniles and non-reproductive individuals. In such patches all individual are nonreproductive, similar to the situation in early succes- 


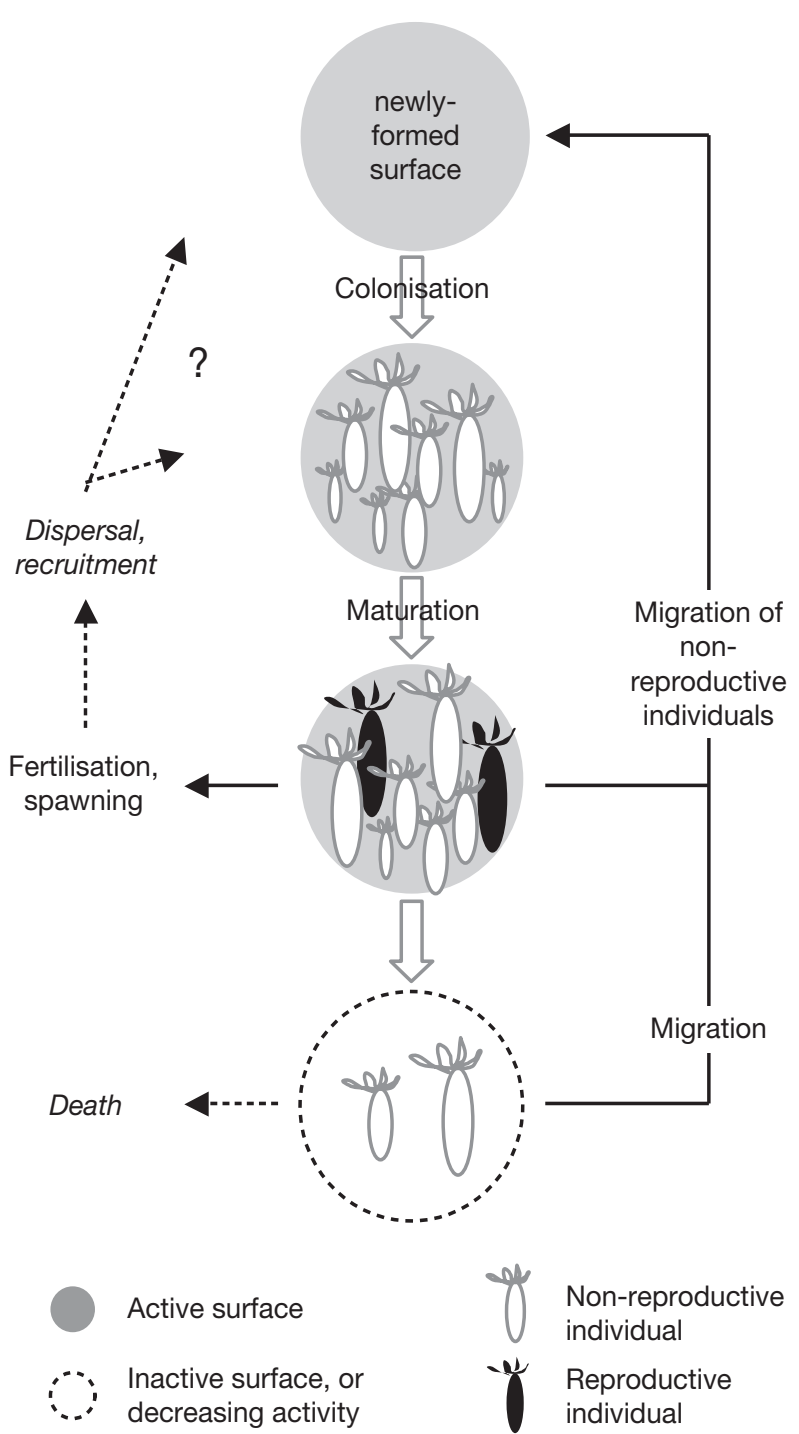

Fig. 8. Alvinella pompejana. Evolution of size- and stagestructure at scale of single patche $\left(\mathrm{dm}^{2}\right)$, in active parts of hydrothermal smokers. Dotted portions of lines represent phases of life history that is unknown

sional stages of P. palmiformis (Copley et al. 2003). Subsequently, mature individuals that were not reproductive at the time of colonisation progressively enter the reproductive phase of their life-cycle. However, in contrast to the older successional stages of $P$. palmiformis, which appear to be synchronised at the patch scale, all $A$. pompejana do not reproduce synchronously. A. pompejana is exposed to a highly fluctuating environment, and must be able to respond very quickly to disturbance. Depending on the migration history of an individual, and the time of its arrival at a suitable patch, it may have little chance of initiating reproduction synchronously with other individuals in the patch.
Acknowledgements. We are grateful to the chief scientists of the different cruises who allowed us to obtain our set of TRAC in situ experiments (J. Childress, H. Felbeck, A. Chave, D. Manahan, F. Lallier), and particularly to C. Fisher who helped us to start the experiments in the Larvae NSF programme. We also thank J. P. Lechaire and P. Briand for their help with on board processing of samples, and $\mathrm{D}$. Desbruyères and $\mathrm{P}$. Rodier for the temperature probes used on the TRAC devices. We thank the captains and crews of the research vessels 'Atlantis II', 'Atalante' and 'Nadir', as well as the crews and pilots of the submersibles 'Alvin' and 'Nautile'. We thank reviewers for their efforts and acknowledge that many of the comments led to improvements in the paper. The research was funded by INSU, CNRS, IFREMER, Dorsales and NSF grant OCE-9712233 to L.S.M.

\section{LITERATURE CITED}

Airoldi L (2000) Responses of algae with different life histories to temporal and spatial variability of disturbance in subtidal reefs. Mar Ecol Prog Ser 195:81-92

Blanchette CA (1996) Seasonal patterns of disturbance influence recruitment of the sea palm, Postelsia palmaeformis. J Exp Mar Biol Ecol 197:1-14

Chevaldonné P (1996) Ecologie des cheminées hydrothermales actives. $\mathrm{PhD}$ thesis, Université de la Méditerranée

Chevaldonné P, Desbruyères D, Le Haître M (1991) Timeseries of temperature from 3 deep-sea hydrothermal vent sites. Deep-Sea Res 38:1417-1430

Chevaldonné P, Jollivet D (1993) Videoscopic study of deepsea hydrothermal vent alvinellid polychaete populations: biomass estimation and behaviour. Mar Ecol Prog Ser 95: 251-262

Copley JT (1998) Ecology of deep-sea hydrothermal vents. $\mathrm{PhD}$ thesis, University of Southampton

Copley JTP, Tyler PA, Van Dover CL, Philp SJ (2003) Spatial variation in the reproductive biology of Paralvinella palmiformis (Polychaeta: Alvinellidae) from a vent field on the Juan de Fuca Ridge. Mar Ecol Prog Ser 255:171-181

Desbruyères D, Laubier L (1986) Les Alvinellidae, une famille d'annélides polychètes inféodées aux sources hydrothermales sous-marines: systématique, biologie et écologie. Can J Zool 64:2227-2245

Desbruyères D, Chevaldonné $\mathrm{P}$, Alayse-Danet AM, Jollivet $\mathrm{D}$, and 14 others (1998) Biology and ecology of the 'Pompeï worm' (Alvinella pompejana, Desbruyères et Laubier), a normal dweller of an extreme deep-sea environment: a synthesis of current knowledge and recent developments. Deep-Sea Res II 45:383-422

Dethier MN (1984) Disturbance and recovery in intertidal pools: maintenance of mosaic patterns. Ecol Monogr 54: 99-118

Fustec A, Desbruyères D, Juniper SK (1987) Deep-sea hydrothermal vent communities at $13^{\circ} \mathrm{N}$ on the Est Pacific Rise: microdistribution and temporal variations. Biol Oceanogr $4: 121-164$

Gaill F, Hunt S (1991) The biology of annelid worms from high temperature hydrothermal vent regions. Rev Aquat Sci 4:107-137

Gaill F, Felbeck H, Desbruyères D, Lallier FH, Toulmond A, and 25 others (1996) Hot 96. InterRidge News 5:22-24

Johnson KS, Childress JJ, Beehler CL, Sakamoto CM (1994) Biogeochemistry of hydrothermal vent mussel communities: the deep-sea analogue to the intertidal zone. DeepSea Res 41:993-1011

Jollivet D (1993) Distribution et évolution de la faune asso- 
ciée aux sources hydrothermales à $13^{\circ} \mathrm{N}$ sur la dorsale du Pacifique Oriental: le cas particulier des polychètes Alvinellidae. $\mathrm{PhD}$ thesis, Université de Bretagne Occidentale

Juniper SK, Martineu P (1995) Alvinellids and sulfides at hydrothermal vents of the eastern Pacific: a review. Am Zool 35:174-185

Juniper SK, Sarrazin J (1995) Interaction of vent biota and hydrothermal deposits: present evidence and future experimentation. In: Humphris SE, Zierenberg RA, Mullineaux LS, Thomson RE (eds) Seafloor hydrothermal systems: physical, chemical, biological and geological interactions. American Geophysical Union, Washington, DC, p 178-193

Juniper SK, Jonasson IR, Tunnicliffe V, Southward AJ (1992) Influence of a tube-building polychaete on hydrothermal chimney mineralisation. Geology 20:895-898

Kukert H, Smith CR (1992) Disturbance, colonization and succession in a deep-sea sediment community: artificialmound experiments. Deep-Sea Res 39:1349-1371

Le Bris N, Zbinden M, Gaill F (2005) Processes controlling the physico-chemical micro-environments associated with Pompeii worms. Deep-Sea Res I 52:1071-1083

Levin LA (1984) Life history and dispersal patterns in a dense infaunal polychaete assemblage: community structure and response to disturbance. Ecology 65:1185-1200

Lutz RA, Jablonski D, Turner RD (1984) Larval development and dispersal at deep-sea hydrothermal vents. Science 226:1451-1453

McHugh D (1989) Population structure and reproductive biology of 2 sympatric hydrothermal vent polychaetes, Paralvinella pandorae and Paralvinella palmiformis. Mar Biol 103:95-106

Mullineaux LS, Peterson CH, Micheli F, Mills SW (2003) Successional mechanism varies along a gradient in hydrothermal fluid flux at deep-sea vents. Ecol Monogr 73:523-542

Olive PJW (1970) Reproduction of a Northumberland population of the polychaete Cirratulus cirratus. Mar Biol 5: 259-273

Pradillon F, Gaill F (2003) Oogenesis characteristics in the hydrothermal vent polychaete Alvinella pompejana. Invertebr Reprod Dev 3:223-235

Pradillon F, Shillito B, Young CM, Gaill F (2001) Developmental arrest in vent worm embryos. Nature 413:698-699

Ramirez Llodra E (2002) Fecundity and life-history strategies in marine invertebrates. Adv Mar Biol 43:87-170

Santos SL, Simon JL (1980) Marine soft-bottom community establishment following annual defaunation: larval or adult recruitment? Mar Ecol Prog Ser 2:235-241

Sarradin PM, Caprais JC, Briand P, Gaill F, Shillito B, Desbruyères $D$ (1998) Chemical and thermal description of the environment of the Genesis hydrothermal vent community (13N N, EPR). Cah Biol Mar 39:159-167

Sarrazin J, Juniper SK (1999) Biological characteristics of a hydrothermal edifice mosaic community. Mar Ecol Prog Ser 185:1-19

Sarrazin J, Robigou V, Juniper SK, Delaney JR (1997) Biolog-

Editorial responsibility: Otto Kinne (Editor-in-Chief), Oldendorf/Luhe, Germany ical and geological dynamics over 4 years on a hightemperature sulfide structure at the Juan de Fuca Ridge hydrothermal observatory. Mar Ecol Prog Ser 153:5-24

Sarrazin J, Juniper SK, Massoth GJ, Legendre P (1999) Physical and chemical factors influencing species distributions on hydrothermal sulfide edifices of the Juan de Fuca Ridge, northeast Pacific. Mar Ecol Prog Ser 190:89-112

Shull DH (1997) Mechanisms of infaunal polychaete dispersal and colonization in an intertidal sandflat. J Mar Res 55: 153-179

Smith CR, Brumsickle SJ (1989) The effects of patch size and substrate isolation on colonization modes and rates in an intertidal sediment. Limnol Oceanogr 34:1263-1277

Smith CR, Hessler RR (1987) Colonization and succession in deep-sea ecosystems. Trends Ecol Evol 2:359-363

Smith CR, Jumars PA, DeMaster DJ (1986) In situ studies of megafaunal mounds indicate rapid sediment turnover and community response at the deep-sea floor. Nature 323:251-253

Sokal RR, Rohlf FJ (1995) Biometry: the principles and practice of statistics in biological research, 3rd edn. WH Freeman, New York

Sousa WP (1984) Intertidal mosaics: patch size, propagule availability, and spatially variable patterns of succession. Ecology 65:1918-1935

Sousa WP (1985) Disturbance and patch dynamics on rocky intertidal shores. In: Pickett STA, White PS (eds) The ecology of natural disturbance and patch dynamics. Academic Press, Orlando, FL, p 101-124

Sousa WP (2001) Natural disturbance and the dynamic of marine benthic communities. In: Bertness MD (ed) Marine community ecology. Sinauer Associates, Sunderland, MA, p 85-130

Taylor CD, Wirsen CO, Gaill F (1999) Rapid microbial production of filamentous sulfur mats at hydrothermal vents. Appl Environ Microbiol 65:2253-2255

Tunnicliffe V, Juniper SK (1990) Dynamic character of the hydrothermal vent habitat and the nature of sulfide chimney fauna. Prog Oceanogr 24:1-13

Tunnicliffe V, Desbruyères D, Jollivet D, Laubier L (1993) Systematic and ecological characteristics of Paralvinella sulfincola Desbruyères and Laubier, a new polychaete (family Alvinellidae) from northeast Pacific hydrothermal vents. Can J Zool 71:286-297

Tunnicliffe V, Embley RW, Holden JF, Butterfield DA, Massoth GJ, Juniper SK (1997) Biological colonization of new hydrothermal vents following an eruption on Juan de Fuca Ridge. Deep-Sea Res II 44:1627-1644

Zal F, Jollivet D, Chevaldonné $P$, Desbruyères D (1995) Reproductive biology and population structure of the deep-sea hydrothermal vent worm Paralvinella grasslei (Polychaeta: Alvinellidae) at $13^{\circ} \mathrm{N}$ on the East Pacific Rise. Mar Biol 122:637-648

Zbinden M, Le Bris N, Compère P, Martinez I, Guyot F, Gaill F (2003) Mineralogical gradients associated with alvinellids at deep-sea hydrothermal vents. Deep-Sea Res I 50: 269-280

Submitted: February 27, 2004; Accepted: May 21, 2005

Proofs received from author(s): September 10, 2005 